\title{
Projeto de Controle Fuzzy para Aprimorar a Eficiência Energética de Secadores Rotativos
}

\author{
Modesto P. Júnior* Santino M. Bitarães** \\ Thiago A. M. Euzébio** \\ * Schneider Electric Brasil, Universidade Federal de Minas Gerais, \\ Belo Horizonte, MG, (e-mail: modesto.junior@se.com). \\ ** Instituto Tecnológico Vale, Ouro Preto, MG, (e-mail: \\ santinobitaraes@gmail.com, thiago.euzebio@itv.org )
}

\begin{abstract}
This article describes a fuzzy control project for rotary drying. The goal is to reduce the energy consumption of the process without losing the quality of the final product. Different from other approaches, the proposal takes into account, the difficulties of the modeling process and the instrumentation limitations in the industrial reality. According to the results, fuzzy control implementation reduces the consumption of biomass by $9 \%$, which represents an annual reduction of 648 tons of carbon dioxide emissions $\left(\mathrm{CO}_{2}\right)$ to the atmosphere.

Resumo: O projeto de um controle fuzzy para secagem rotativa é descrito nesse artigo. O objetivo é reduzir o consumo de energia do processo sem perder a qualidade do produto final. Diferente de outras abordagens, a proposta desse artigo leva em consideração as dificuldades da modelagem do processo e as limitações de instrumentação na realidade industrial. De acordo com os resultados, a implantação do controle fuzzy reduziu em $9 \%$ o consumo de biomassa, o que representa uma redução anual de 648 toneladas de emissão de dióxido de carbono $\left(\mathrm{CO}_{2}\right)$ para a atmosfera.
\end{abstract}

Keywords: Fuzzy Control; Rotary Dryer; Energy Eficiecy.

Palavras-chaves: Controle Fuzzy; Secador Rotativo; Eficiência Energética.

\section{INTRODUÇÃO}

Secagem rotativa de granulados é um método de secagem usado em indústrias diversas. Na literatura há exemplos nas indústrias de mineração (Wu et al., 2010), de processamento de produtos agrícolas (Delele et al., 2015) e de químicos e fertilizantes (Arruda et al., 2009). O objetivo primário da secagem é o de reduzir a umidade do material processado. Assim, é possível retardar a deterioração biológica ou química dos produtos. Outro benefício é que o produto seco diminui sua densidade aparente, o que reduz custos de transporte.

A umidade é retirada dos granulados por troca de calor. Uma corrente de ar quente é forçada a ter contato com o granulado úmido dentro do secador. O secador gira continuamente para aumentar a superfície de contato entre o ar quente e o material úmido, por isso o nome secador rotativo. De acordo com Mujumdar (2014), a eficiência térmica de secadores rotativos está na faixa de 30 a $60 \%$.

Questões operacionais podem levar o sistema de secagem a um baixo desempenho energético. A taxa mássica, umidade e granulometria do produto variam com o tempo, por consequência, o valor de carga térmica requerida para a secagem também varia com o tempo. A biomassa usada na queima na fornalha tem variações granulométricas e

\footnotetext{
* O presente trabalho foi realizado com apoio da Coordenação de Aperfeiçoamento de Pessoal de Nível Superior - Brasil (CAPES) Código de Financiamento 001.
}

de umidade que afetam a temperatura do gás quente que alimenta o secador. Caso ajustes operacionais contínuos não sejam feitos, o sistema consome mais biomassa que o necessário ou produz um material fora da especificação de umidade.

É prática comum na indústria que as variáveis operacionais de um sistema de secagem rotativa sejam controladas por operadores em uma sala de controle. A eficiência da operação fica, portanto, dependente do conhecimento do operador do turno. Essa estratégia, além de promover uma despadronização de ações, é refém de tomadas de decisões erradas ou atrasadas. Uma estratégia alternativa é a aplicação de controle avançado (Yliniemi et al., 1998; Didriksen, 2002; Ortega et al., 2007; Pablo et al., 2016) para que o sistema de secagem rotativa opere de modo automático e com menor intervenção humana.

Esse artigo apresenta o projeto de um controle fuzzy e os resultados de sua aplicação em uma planta de secagem rotativa de fertilizantes. $\mathrm{O}$ controlador projetado funciona em uma camada acima da camada básica de controle regulatório já existente na planta. O objetivo é reduzir o consumo de energia pela queima de biomassa sem perda de qualidade do produto processado. Diferente das técnicas existentes na literatura, a proposta de controle desse artigo independe do modelo do processo, a instrumentação necessária é básica e de baixo custo, e a razão estequiométrica é uma variável manipulada. 
Além da Introdução, esse artigo é formado por outras seis seções. A Seção 2 descreve as características das principais contribuições na literatura de controle avançado para secadores rotativos. A planta estudada nesse artigo é descrita na Seção 3. As estratégias de controle regulatória e a fuzzy proposta são detalhadas nas Seções 4 e 5 , respectivamente. Os resultados da aplicação do controle fuzzy e a análise com resultados da estratégia com controle regulatório são descritos na Seção 6. Os comentários finais estão na Seção 7.

\section{REVISÃO BIBLIOGRÁFICA}

Desde o início dos estudos formais sobre o controle de secadores rotativos, muitas técnicas de controle foram propostas. Nesta seção, as técnicas mais citadas na literatura são detalhadas. Todas essas abordagens apresentam algumas vantagens e limitações.

Uma estrutura de controle híbrido aplicada a uma planta piloto de secador rotativo foi proposta por Yliniemi et al. (1998). A única variável manipulada nessa estrutura é a vazão de combustível. As variáveis monitoradas são a temperatura do ar seco e a umidade do material na entrada e na saída do secador. A razão estequiométrica de ar/combustível e a vazão do ar de exaustão não são consideradas nessa estrutura de controle.

Em (Didriksen, 2002) um controlador preditivo por modelo é estudado para o caso de um secador rotativo de uma indústria de açúcar. A temperatura do gás de exaustão é controlada pela variação na vazão do material úmido que passa pelo secador rotativo. Algumas aproximações distantes da realidade industrial são assumidas: a temperatura do gás na saída da fornalha é constante e a vazão de combustível não é manipulada. A aplicação é feita apenas em simulador.

Ortega et al. (2007) analisaram a aplicação de um controle robusto $H_{\infty}$ em um secador rotativo para areia úmida. O sistema é considerado multivariável, a temperatura do gás de exaustão e a umidade do material são controladas pela manipulação da vazão de combustível e da vazão de material úmido. $\mathrm{O}$ controle aplicado exige o conhecimento do modelo não linear da planta controlada.

As técnicas MPC não linear, GPC e PID são comparadas em (Pablo et al., 2016). Os sistemas de controle estudados são aplicados em uma planta piloto de secador rotativo para sementes de cacau. A temperatura do gás de saída do secador é controlada pela vazão de combustível GLP. $\mathrm{O}$ estudo indica um melhor desempenho para o MPC não linear, apesar da complexidade do projeto comparada às outras técnicas.

Grande parte das técnicas de controle existentes para secadores rotativos são de uma entrada e uma saída. Variáveis como pressão interna do secador e vazão de exaustão são negligenciadas. É difícil admitir que com tão poucas variáveis sendo monitoradas, o secador rotativo opere de fato em modo automático. Outro ponto negativo dessas técnicas é a necessidade de se conhecer o modelo do processo de secagem rotativa. As dificuldades de se levantar o modelo não linear desse sistema são descritas em (Wang et al., 2015). As propostas revisadas também se distanciam da realidade industrial ao exigirem sensores de umidade online, ainda pouco encontrados no chão de fábrica por serem de alto custo e de difícil manutenção.

\section{DESCRIÇÃO DA PLANTA DE SECAGEM}

O controle fuzzy foi desenvolvido e aplicado na unidade de produção de fertilizantes da empresa Yara no complexo industrial de Paulínia/SP. O diagrama esquemático da planta do secador rotativo é apresentado na Figura 1. O material a ser seco é alimentado em um tambor rotativo pelo material proveniente da etapa de granulação. O comprimento do tambor é de 24 metros e 3,5 metros de diâmetro. $\mathrm{O}$ ar de secagem é fornecido por um ventilador e é aquecido pela queima de gases em uma fornalha. A biomassa de cavaco de madeira é usada como combustível. $\mathrm{O}$ produto seco é enviado às etapas de resfriamento e peneiramento. A parcela desse produto na faixa entre $2 \mathrm{e}$ $4 \mathrm{~mm}$ é enviada ao armazém de estoque e a outra parcela retorna ao processo.

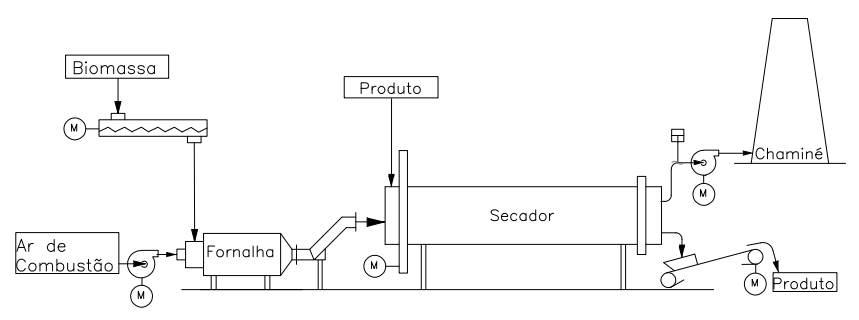

Figura 1. Processo de secagem de fertilizantes.

O fertilizante na entrada do secador tem um teor de umidade entre 10 e $15 \%$. O principal requisito do sistema é secar o fertilizante a um teor de umidade menor que $2,5 \%$. O produto é seco para endurecer os grãos e evitar desintegração ou empedramento dos grânulos nos armazéns e embalagens.

A taxa de alimentação do fertilizante é controlada pelo operador. A velocidade de rotação e a inclinação do secador são fixas. $\mathrm{O}$ arraste gerado pelo gás quente em movimento varia em função da abertura da válvula do ar de exaustão, da quantidade de alimentação do produto e da própria temperatura do gás. A temperatura do gás varia em função das vazões de ar de combustão e biomassa, da proporção estequiométrica entre estas, do poder calorífico e da umidade da biomassa utilizada.

Não há um instrumento de medição de umidade online na planta. Essa limitação acontece em grande parte dos sistemas de secagem rotativa devido ao alto custo de compra e manutenção do instrumento de medição de umidade em tempo real. A umidade na saída do secador é inferida por meio da temperatura do gás de exaustão. Essa forma de inferência da umidade é prática comum na indústria e bem documentada em (Park et al., 2014) e (Moyers and Baldwin, 1997). Para a planta em estudo, uma temperatura do gás de exaustão acima de $95^{\circ} \mathrm{C}$ garante uma umidade abaixo de $2,5 \%$ no produto. 


\section{SISTEMA DE CONTROLE REGULATÓRIO}

Existem três malhas de controle regulatório na planta. $\mathrm{Na}$ Figura 2, as malhas de controle são representadas pelos blocos TIC02, TIC03 e FIC01. As TIC02 e 03 controlam a temperatura na saída da fornalha, a primeira por meio da vazão de ar de combustão e a segunda por meio da vazão de biomassa. Já a FIC01 manipula a válvula de exaustão para controlar a vazão de ar entre o secador e a chaminé. O controlador PID é usado nas malhas TIC02 e FIC01, uma lógica baseada em regras é usada na malha TIC03.

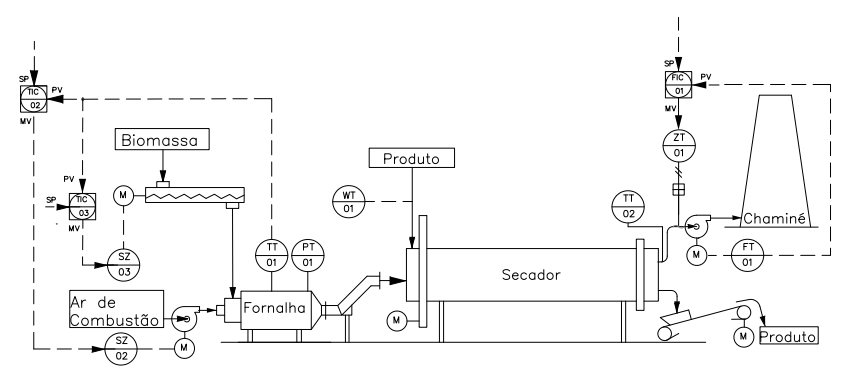

Figura 2. Camada de controle regulatório na planta de secagem rotativa.

O objetivo da estratégia de controle nessa abordagem é manter o setpoint de temperatura na saída da fornalha fixo e igual a $1025^{\circ} \mathrm{C}$. A taxa de alimentação de fertilizantes no secador e o setpoint da malha de vazão de ar de exaustão são modificadas ao longo do tempo pelo operador. O operador também monitora constantemente a temperatura do gás de exaustão para que esta seja igual a $95^{\circ} \mathrm{C}$.

\section{SISTEMA DE CONTROLE FUZZY PROPOSTO}

Como apresentado em (Precup and Hellendoorn, 2011), o projeto e implementação de controle fuzzy têm sido bem aceitos em aplicações industriais. Duas razões se destacam: (i) não precisa de modelo do processo, que em alguns casos é bem complexo de se identificar e (ii) insere ao controlador de forma simples o conhecimento prévio dos responsáveis pela operação. Este último argumento é especialmente importante para o uso prolongado e manutenção do sistema de controle implantado, como pode ser visto em resultados de implantação de controle fuzzy em (Júnior et al., 2018) e (Magalhães and Euzébio, 2018).

A Figura 3 ilustra o diagrama de processo com a nova estratégia de controle. O controlador fuzzy manipula três variáveis do processo: o setpoint da malha de vazão de gás de exaustão, o setpoint da malha de vazão do ar de combustão e a vazão de biomassa que alimenta a fornalha. Quanto menor a vazão do gás de exaustão, maior o tempo de residência do gás quente no secador e, portanto, maior a troca de calor entre o ar quente e o fertilizante úmido. A razão estequiométrica é regulada com o passar do tempo de acordo com as variações no ar de combustão e na vazão mássica de biomassa na fornalha.

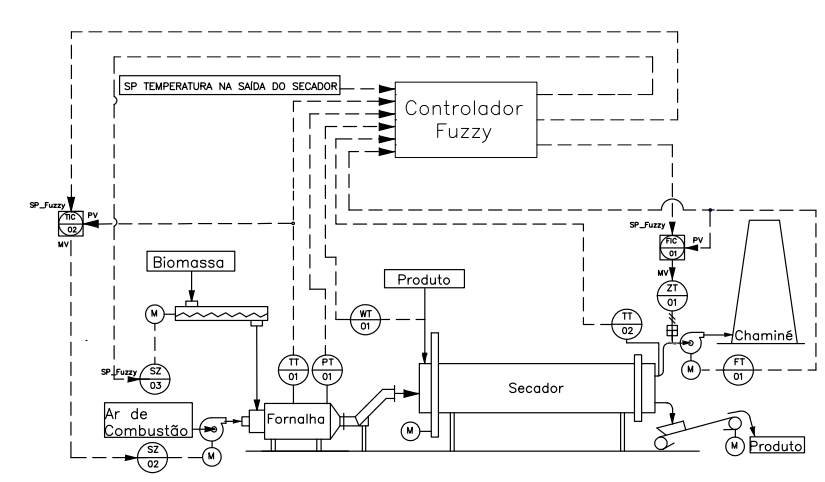

Figura 3. Controlador fuzzy e a interligação com o processo e o controle regulatório.

O principal objetivo do sistema de controle proposto é manter a temperatura do gás na saída do secador a mais próxima do valor ótimo estabelecido para o processo de secagem. Diferente da estratégia apenas com controle regulatório, a temperatura do gás na saída do secador passa a seguir um setpoint. Devido à sua importância na qualidade do produto final, esta é a única variável de processo a seguir um setpoint.

Foram criadas 19 regras de controle, listadas na Tabela 1, a partir da capacidade dos especialistas em informar verbalmente como a alterações das variáveis do processo influenciam na dinâmica do processo, e consequentemente, na qualidade do produto. As regras foram formuladas como a seguir:

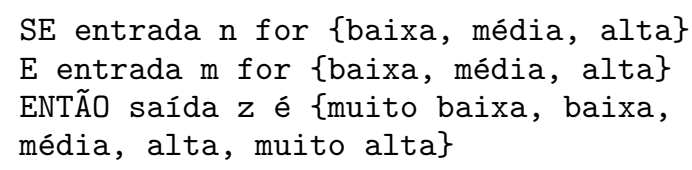

Devido ao acoplamento entre as variáveis, foram utilizadas funções de pertinência trapezoidais, já que estas apresentam transição mais suave entre os valores. As Figuras 4 e 5 ilustram as funções de pertinência para as seis entradas e para as três saídas, respectivamente.

\section{RESULTADOS E DISCUSSÃO}

O controlador fuzzy foi projetado no programa FuzzyDesigner da Rockwell Automation e está em operação em um dos SDCDs da planta de Granulação do Complexo Industrial da Paulínia, uma unidade de produção de fertilizantes da Yara.

A análise de desempenho do controlador fuzzy foi feita com base em um período de 16 horas. Durante esse período não houve intervenção dos operadores na camada de controle regulatório ou em qualquer outro atuador em campo. A Figura 6 apresenta a temperatura do ar na saída do secador e seu respectivo setpoint. Durante o período analisado houve uma máxima de $109^{\circ} \mathrm{C}$ e uma mínima de $78^{\circ} \mathrm{C}$. 
Tabela 1. Regras do controlador Fuzzy.

\begin{tabular}{|c|c|c|c|c|c|c|c|c|c|}
\hline \multicolumn{7}{|c|}{ Entradas Fuzzy } & \multicolumn{3}{|l|}{ Saídas Fuzzy } \\
\hline $\mathrm{N}^{\circ}$ & $\begin{array}{l}\text { Temp. } \\
\text { Fornalha }\end{array}$ & $\begin{array}{l}\text { Temp. } \\
\text { Secador }\end{array}$ & $\begin{array}{l}\text { Vazão Ar } \\
\text { Exaustão }\end{array}$ & $\begin{array}{l}\text { Vazão } \\
\text { Produto }\end{array}$ & $\begin{array}{l}\text { Pressão } \\
\text { Fornalha }\end{array}$ & $\begin{array}{l}\text { SP Temp. } \\
\text { Secador }\end{array}$ & $\begin{array}{l}\text { Vazão } \\
\text { Biomassa }\end{array}$ & $\begin{array}{l}\text { Vazão Ar } \\
\text { Combustão }\end{array}$ & $\begin{array}{l}\text { Abertura } \\
\text { Válvula Ar } \\
\text { Exaustão }\end{array}$ \\
\hline 1 & & & BAIXO & BAIXO & BAIXO & & & MÉDIO & \\
\hline 2 & & & BAIXO & ALTO & BAIXO & & & & ALTO \\
\hline 3 & & & ALTO & & BAIXO & & & & ALTO \\
\hline 4 & & & BAIXO & BAIXO & ALTO & & & & BAIXO \\
\hline 5 & & & BAIXO & ALTO & ALTO & & & & MÉDIO \\
\hline 6 & & & ALTO & & ALTO & & & & ALTO \\
\hline 7 & MÉDIO & BAIXO & & BAIXO & & $\overline{\mathrm{BAIXO}}$ & MÉDIO & ALTO & \\
\hline 8 & BAIXO & BAIXO & & BAIXO & & $\overline{\mathrm{BAIXO}}$ & ALTO & MUITO ALTO & \\
\hline 9 & MÉDIO & BAIXO & & ALTO & & $\overline{\mathrm{BAIXO}}$ & ALTO & MUITO ALTO & \\
\hline 10 & BAIXO & BAIXO & & ALTO & & $\overline{\mathrm{BAIXO}}$ & MUITO ALTO & MUITO ALTO & \\
\hline 11 & ALTO & BAIXO & & ALTO & & ALTO & ALTO & MUITO ALTO & \\
\hline 12 & BAIXO & MÉDIO & & BAIXO & & MÉDIO & BAIXO & MÉDIO & \\
\hline 13 & MÉDIO & MÉDIO & & BAIXO & & MÉDIO & BAIXO & MÉDIO & \\
\hline 14 & MÉDIO & MÉDIO & & ALTO & & MÉDIO & MÉDIO & ALTO & \\
\hline 15 & ALTO & MÉDIO & & ALTO & & MÉDIO & BAIXO & MÉDIO & \\
\hline 16 & ALTO & ALTO & & BAIXO & & $\overline{\mathrm{ALTO}}$ & MUITO BAIXO & MUITO BAIXO & \\
\hline 17 & MÉDIO & ALTO & & BAIXO & & MÉDIO & MUITO BAIXO & BAIXO & \\
\hline 18 & MÉDIO & ALTO & & ALTO & & $\overline{\mathrm{ALTO}}$ & MUITO BAIXO & BAIXO & \\
\hline 19 & ALTO & ALTO & & ALTO & & $\overline{\mathrm{ALTO}}$ & MUITO BAIXO & MUITO BAIXO & \\
\hline
\end{tabular}
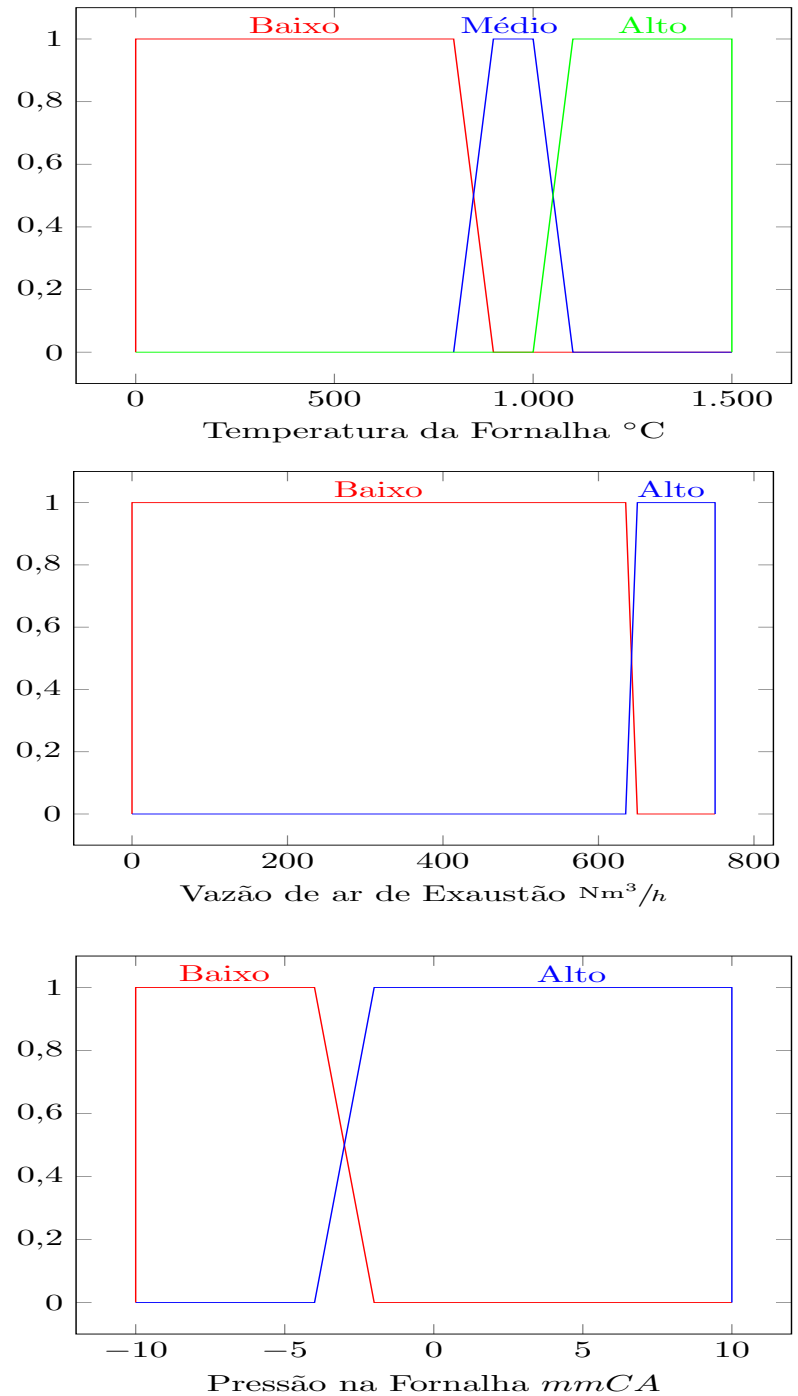

Figura 4. Funções de pertinência para as entradas fuzzy
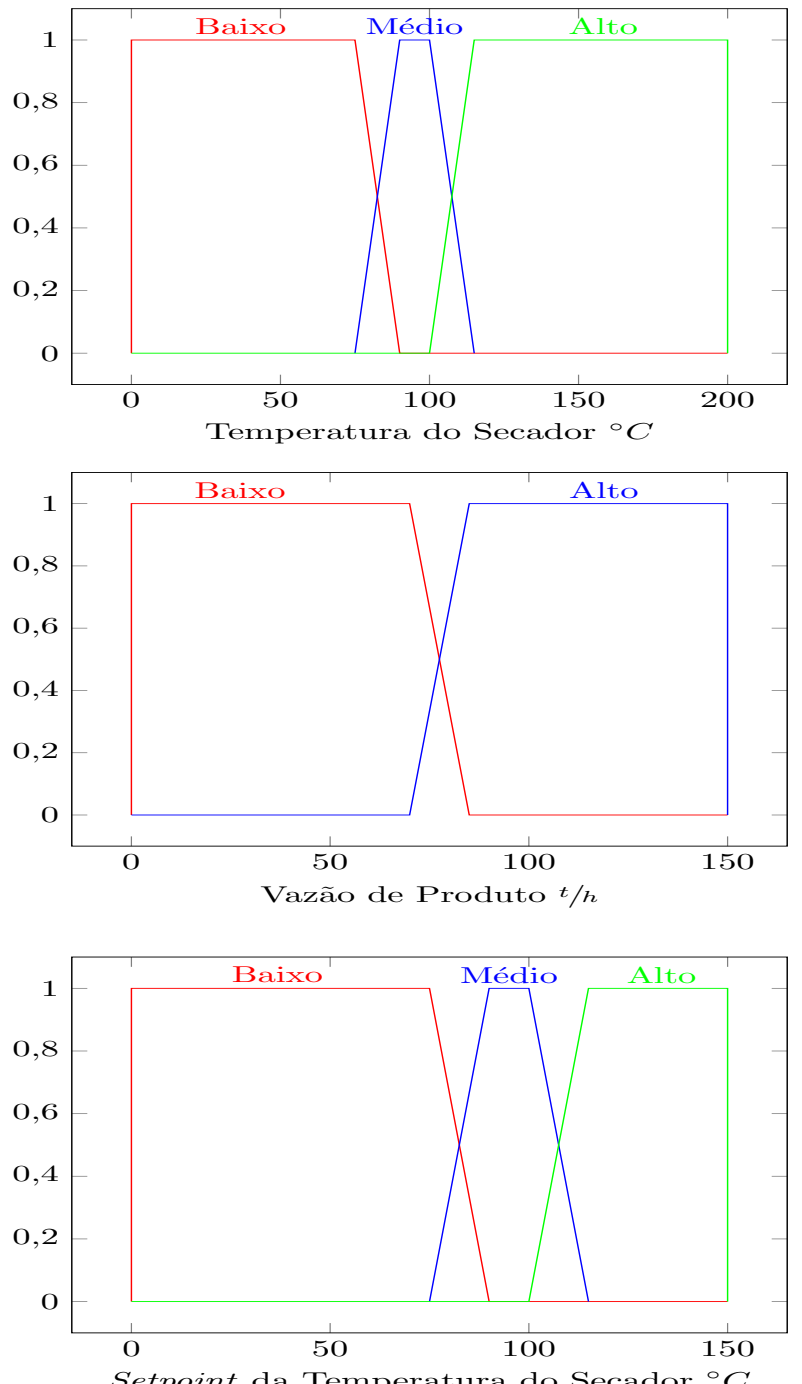

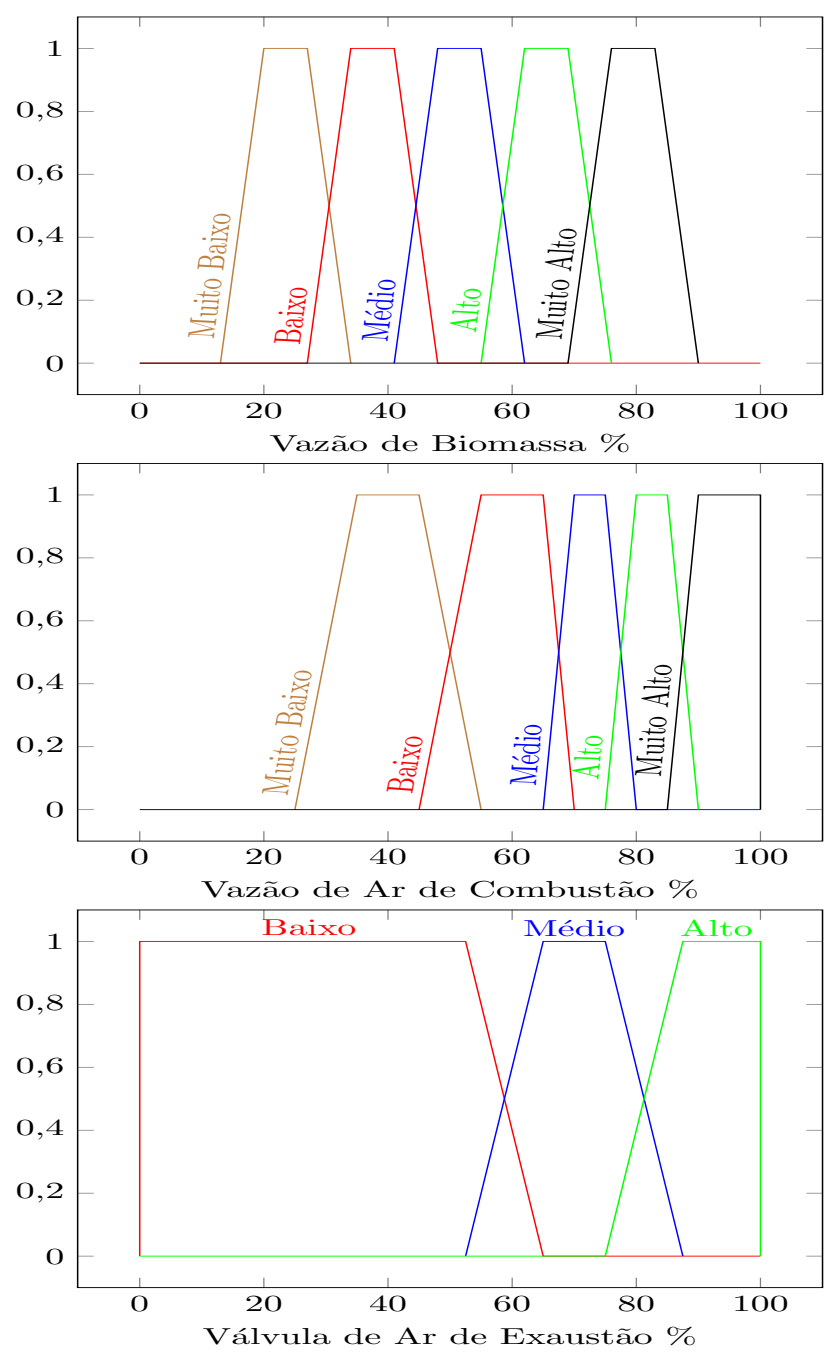

Figura 5. Funções de pertinência das saídas fuzzy

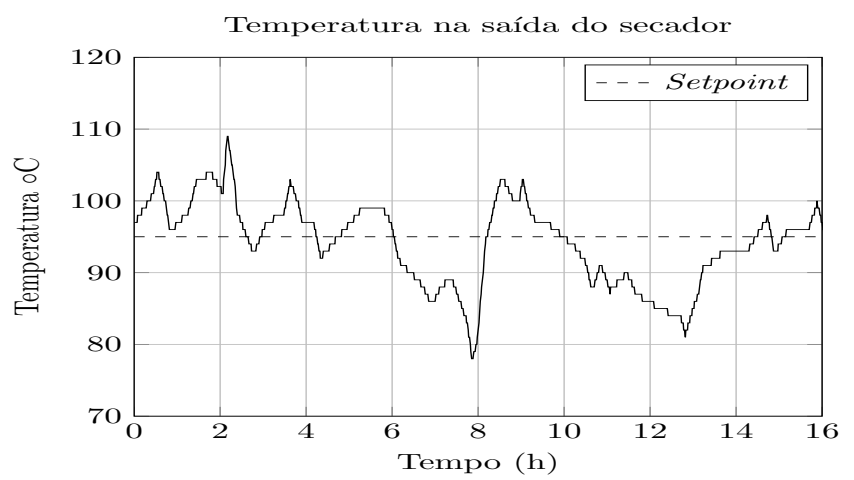

Figura 6. Temperatura na saída do secador com a estratégia de controle proposta.

O resultado obtido com o controle fuzzy é comparado com o resultado da estratégia anterior baseada nas decisões da operação. Foi utilizado um conjunto de dados correspondente a 16 horas de funcionamento da planta. A Figura 7 apresenta a análise estatística por boxplot da temperatura de saída do secador para as duas estratégias. São observadas uma mediana de $95,31^{\circ} \mathrm{C}$ para a estratégia com controle fuzzy e $90,58^{\circ} \mathrm{C}$ para a estratégia anterior.
A variabilidade da temperatura do secador aumentou com a estratégia de controle fuzzy, mas a mediana ficou mais próxima à temperatura ideal de $95^{\circ} \mathrm{C}$.

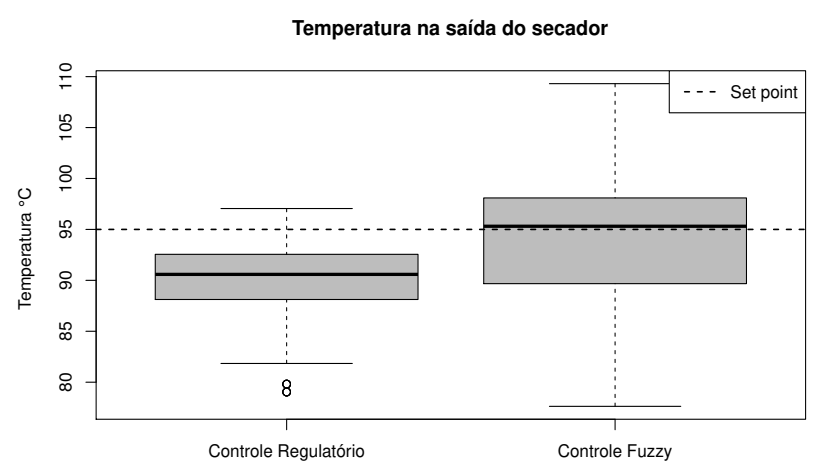

Figura 7. Boxplot da temperatura na saída do secador com a operação do controle fuzzy e controle regulatório.

O desempenho do controlador fuzzy e do controle regulatório também foram avaliados por meio do índice de Harris (Desborough and Harris, 1992) e da integral do valor absoluto do erro (IAE), Tabela 2. A aplicação do controle fuzzy reduziu em $37 \%$ o IAE da temperatura da saída do secador em função da referência. A nova estratégia apresentou ainda uma melhora de $44 \%$ no índice de Harris.

Tabela 2. Índices de desempenho.

\begin{tabular}{lll}
\hline Índice & $\begin{array}{l}\text { Controle } \\
\text { Fuzzy }\end{array}$ & $\begin{array}{l}\text { Controle } \\
\text { Regulatório }\end{array}$ \\
\hline IAE & 76,62 & 120,71 \\
Harris & 0,13 & 0,09 \\
\hline
\end{tabular}

$\mathrm{Na}$ estratégia de controle apenas com as malhas do regulatório, o setpoint de temperatura da fornalha era mantido fixo em $1025^{\circ} \mathrm{C}$. A Figura 8 apresenta o valor da temperatura na saída da fornalha para a nova estratégia fuzzy. Para essa nova abordagem, a temperatura permaneceu mais de $85 \%$ do tempo abaixo de $1025^{\circ} \mathrm{C}$.

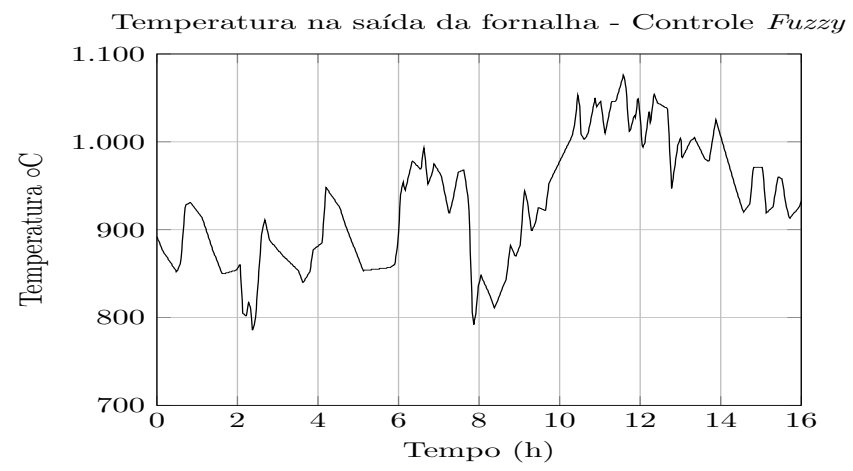

Figura 8. Temperatura na saída da fornalha.

De acordo com o boxplot na Figura 9, a mediana da temperatura que era de $1.010,75^{\circ} \mathrm{C}$ com controle regulatório reduziu a uma mediana de $926,33^{\circ} \mathrm{C}$ com a estratégia fuzzy. 
A menor temperatura na fornalha implica em um menor consumo de biomassa. É importante salientar que o menor consumo de biomassa não prejudicou a temperatura na saída do secador. A temperatura na saída do secador teve um aumento médio de $3,9^{\circ} \mathrm{C}$.

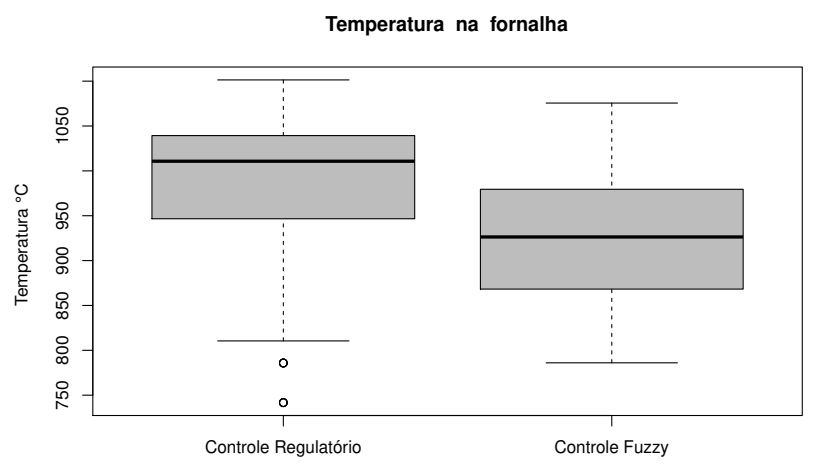

Figura 9. Boxplot da temperatura na fornalha - Controle fuzzy e regulatório

Durante o período de testes das estratégias de controle, o consumo de biomassa caiu de 54,2 t para 49,3 t com o controle fuzzy. Essa redução de $9 \%$ de consumo de biomassa corresponde a uma economia anual de $\mathrm{R} \$ 486.000,00$.

O material da biomassa contém cerca de $40 \%$ de carbono em peso, com o restante de hidrogênio $(6,7 \%)$ e de oxigênio $(53,3 \%)$. Dada uma estimativa de consumo de 18.000 t de biomassa por ano, a aplicação do controlador fuzzy pode obter a redução de 648 t por ano na emissão de dióxido de carbono $\left(\mathrm{CO}_{2}\right)$ na atmosfera. De acordo com Nowak et al. (2013), seria necessário $84.265 \mathrm{~m}^{2}$ de área de floresta urbana para obter a mesma redução de dióxido de carbono na atmosfera.

A aplicação do controlador fuzzy também resultou em ganhos intangíveis. Durante o período de operação, os operadores não fizeram nenhuma alteração nas variáveis que o sistema fuzzy controlava. Dessa forma foi possível dedicar atenção a outras áreas da planta que eram monitoradas com menor frequência. Houve ainda grande satisfação dos operadores por verificar que o próprio conhecimento foi utilizado na elaboração das regras utilizadas no controlador.

\section{CONCLUSÃO}

Foi desenvolvido um controlador fuzzy e aplicado ao processo de secagem rotativa em uma planta de produção de fertilizantes. As regras e funções de pertinência foram desenvolvidas com base no conhecimento dos especialistas do processo e embarcadas no SDCD existente. A aplicação do controle fuzzy tornou o processo de secagem automático e sem a interferência humana. A variável de maior interesse nesse sistema, a temperatura na saída do secador, obteve o valor médio de $94,2^{\circ} \mathrm{C}$ para um setpoint de $95^{\circ} \mathrm{C}$ durante o período de teste. Esse bom resultado para a qualidade do produto foi obtido com redução de $9 \%$ no consumo de biomassa e consequente redução da emissão de $\mathrm{CO}_{2}$ para a atmosfera. Como trabalho futuro, pretende-se aprimorar as funções de pertinência para reduzir a variabilidade no processo e estender o controlador para a operação de granulação do fertilizante.

\section{REFERÊNCIAS}

Arruda, E., Façanha, J., Pires, L., Assis, A., and Barrozo, M. (2009). Conventional and modified rotary dryer: Comparison of performance in fertilizer drying. Chemical Engineering and Processing: Process Intensification, 48(9), 1414-1418.

Delele, M.A., Weigler, F., and Mellmann, J. (2015). Advances in the application of a rotary dryer for drying of agricultural products: A review. Drying technology, $33(5), 541-558$.

Desborough, L. and Harris, T. (1992). Performance assessment measures for univariate feedback control. The $\mathrm{Ca}$ nadian Journal of Chemical Engineering, 70(6), 11861197.

Didriksen, H. (2002). Model based predictive control of a rotary dryer. Chemical Engineering Journal, 86(1-2), 53-60.

Júnior, Ê.L., Ferreira, A., Moreira, V., and Euzébio, T. (2018). Fuzzy fault tolerant controller applied in an iron ore concentrate dewatering plant. In $6^{\text {th }}$ International Congress on Automation in Mining. GECAMIN.

Magalhães, S. and Euzébio, T. (2018). Supervisory fuzzy controller for thickener underflow solids concentration on a simulated platform. In $6^{\text {th }}$ International Congress on Automation in Mining. GECAMIN.

Moyers, C.G. and Baldwin, G. (1997). Psychrometry, evaporative cooling, and solids drying. Perry's chemical engineers' handbook, 1-90.

Mujumdar, A.S. (2014). Handbook of industrial drying. CRC press.

Nowak, D.J., Greenfield, E.J., Hoehn, R.E., and Lapoint, E. (2013). Carbon storage and sequestration by trees in urban and community areas of the united states. Environmental pollution, 178, 229-236.

Ortega, M., Castaño, F., Vargas, M., and Rubio, F. (2007). Multivariable robust control of a rotary dryer: Analysis and design. Control Engineering Practice, 15(4), 487500.

Pablo, P.R., William, I.A., José, M., and José, O. (2016). Predictive and adaptive nonlinear controller applied to a drying process of cocoa beans. In 2016 IEEE Ecuador Technical Chapters Meeting (ETCM), 1-6. IEEE.

Park, K.J.B., Park, K.J., Alonso, L.F.T., Cornejo, F.E.P., and Fabbro, I. (2014). Secagem: fundamentos e equações. Revista Brasileira de Produtos Agroindustriais, 16(1), 93-127.

Precup, R.E. and Hellendoorn, H. (2011). A survey on industrial applications of fuzzy control. Computers in industry, 62(3), 213-226.

Wang, X., Qin, B., Xu, H., and Zhu, W. (2015). Rotary drying process modeling and online compensation. Control Engineering Practice, 41, 38-46.

Wu, Z., Hu, Y., Lee, D., Mujumdar, A., and Li, Z. (2010). Dewatering and drying in mineral processing industry: Potential for innovation. Drying Technology, 28(7), 834842.

Yliniemi, L., Koskinen, J., and Leiviskä, K. (1998). Advanced control of a rotary dryer. IFAC Proceedings Volumes, 31(23), 119-124. 